\title{
Novos Cenários de Aprendizagem, Inovação e Sustentabilidade: Uma Pesquisa-Ação na Graduação em Ciências e Tecnologia
}

\author{
Maria Madalena Colette ${ }^{1,2}$, Maria Helena C. da Silva ${ }^{1}$ \\ contato@laboratoriocriativo.art.br, mhco6.silva@gmail.com \\ ${ }^{1}$ Centro Universitário da Serra dos Órgãos / UNIFESO, Campus Pro Arte, Rua Gonçalo de Castro, 85, CEP \\ 25960-090. Teresópólis, Rio de Janeiro, Brasil \\ ${ }_{2}^{2}$ Universidade do Grande Rio / UNIGRANRIO, Campus Lapa II, Rua da Lapa, 86, CEP 20021-180, \\ Centro; Rio de Janeiro, Rio de Janeiro, Brasil
}

DOI: 10.17013/risti.e2.55-69

Resumo: O presente artigo trata de uma Pesquisa-Ação, realizada em 2012 no UNIFESO, voltada à criação de novos cenários de aprendizagem. $\mathrm{O}$ projeto de pesquisa focalizou a criação de formas de apoio às iniciativas empreendedoras dos estudantes relacionadas ao campo de formação. A fase exploratória confirmou hipótese sobre demanda discente por apoio às suas ideias. A fase principal da pesquisa apontou para um descompasso entre a intenção de participação por parte dos estudantes e efetiva participação destes na ação. Entretanto, apesar da queda da presença discente ao longo do projeto, a proposta obteve representativa adesão de docentes e discentes, numa participação mais qualitativa, que entre outros resultados orientou o grupo para a criação de um empreendimento acadêmico. Um novo cenário de aprendizagem concretizou-se na instituição em 2013, com o desenvolvimento da Solução Empresa Junior de Consultoria, liderada por estudantes dos cursos do Centro de Ciências e Tecnologia.

Palavras-Chave: Pesquisa-ação; Sustentabilidade; Cenários de Aprendizagem; Empresa-Junior.

\section{New Learning Scenarios, Innovation and Sustainability: An Action Research in Science and Technology Undergraduate Studies}

Abstract: This article presents an Action Research, held in 2012 in UNIFESO, focusing on the creation of new learning scenarios. The research project focused on creating ways to support entrepreneurial initiatives of the students related to the field of training. The exploratory phase confirmed hypothesis about student demand for support for their ideas. The main phase of the research pointed to a mismatch between the intention of participation by students and effective participation of these in action. However, despite the drop in student presence throughout the project, the proposal has received membership representative of teachers and students in a more qualitative participation, among other results that guided the group to create an academic venture. A new scenario has manifested 
itself in the institution in 2013, with the development of Solution Consulting Company Junior, led by students of the courses at the Center for Science and Technology.

Keywords: Action-Research; Sustainability; Learning Scenarios; Junior Enterprise.

\section{Introdução}

A motivação central do projeto Pesquisa-Ação: Inovação e Sustentabilidade das Iniciativas Discentes teve um cunho pedagógico e fundou-se no entendimento de que, em qualquer tempo e especialmente na atualmente denominada "sociedade do conhecimento", a educação deve corresponder à aprendizagem para a mudança, o que significa dizer aprendizagem para o enfrentamento das mudanças aceleradas que o desenvolvimento tecnológico impulsiona na atualidade. Na visão de Paulo Freire (1981), a educação para se enfrentar o processo de mudança promove a formação da uma consciência crítica, como instrumento maior para a efetivação de transformações significativas, tanto no plano individual quanto no plano global da sociedade.

Trata-se, pois, de uma proposta de pesquisa-ação que pretendeu articular investigação científica com a promoção de ações práticas, através do envolvimento do grupo discente pesquisado - inicialmente estudantes do CCT - Centro de Ciências e Tecnologia do UNIFESO - Centro Universitário da Serra dos Órgãos - e de membros do corpo docente na análise do objeto (Thiolent, 1985).

Enfatizando a importância da inovação tecnológica voltada para o desenvolvimento sustentável de nossa sociedade. Esta pesquisa visou identificar, analisar e incentivar iniciativas discentes empreendedoras, bem como investigar caminhos para o aperfeiçoamento do processo de formação teórico-prático no âmbito do Centro de Ciências e Tecnologia do UNIFESO / CCT.

Em continuidade ao projeto, num segundo ano realizou-se o acompanhamento de empreendimento coletivo resultado de iniciativas discentes fomentadas pelo projeto. Estudantes dos cursos do CCT, apoiados por docentes, lideram o processo de organização, iniciado no ano anterior.

Trata-se de uma estratégia de aproximação da vida acadêmica à realidade profissional, que deverá contribuir para elevar o nível dos profissionais formados e fortalecer a prática institucional no sentido da articulação entre ensino, pesquisa e extensão, voltada ao desenvolvimento sustentável.

Trabalhamos com os empreendedores juniores a partir do conceito de empreendedorismo inovador como uma síntese entre criatividade e sustentabilidade, ou seja, como capacidade de conceber soluções inovadoras, cujos processos de implementação sejam economicamente viáveis, ecologicamente corretos e socialmente justos, quer estas soluções atendam a um empreendimento, a uma comunidade ou à sociedade de uma forma mais ampla. 


\section{Metodologia}

O desenvolvimento desta pesquisa foi embasado na perspectiva metodológica da Pesquisa-ação, que é entendida como uma "pesquisa com base empírica, realizada em estreita associação com uma ação ou com a resolução de um problema coletivo, no qual os participantes representativos da situação ou do problema estão envolvidos de modo cooperativo ou participativo" (Novaes \& Gil, 2010).

A orientação metodológica da pesquisa-ação reflete a perspectiva freireana, que busca reverter à tendência a uma "educação bancária", ainda muito presente na educação, com a promoção da consciência critica. E promove a mudança como permanente movimento transformador do mundo, como busca de melhores condições de vida.

Já Boaventura de Sousa Santos (2009) fala do papel da pesquisa-ação no contexto da universidade no século XXI, como metodologia geradora de projetos e situada na interação entre ensino, pesquisa e extensão. Ele comenta a pesquisa-ação como proposta a ser incentivada para promover a democratização e a emancipação através das práticas universitárias.

A pesquisa-ação é uma metodologia de investigação que busca superar um dos maiores impasses a serem enfrentados pelos educadores: a relação entre teoria e prática (Santos, 2009). Trata-se de uma metodologia de pesquisa na qual há interação entre pesquisadores e pessoas implicadas na situação investigada com o objetivo de resolver ou esclarecer o problema em questão e cujo processo favorece o aumento do conhecimento de todas as pessoas envolvidas no processo (Miranda \& Resende, 2006).

O projeto contou com uma equipe de pesquisadores do CCT, composta por três docentes e quatro discentes em iniciação científica, cujo desenvolvimento seguiu as quatro etapas clássicas da metodologia da Pesquisa-ação: a fase exploratória, a principal, a de ação e a de avaliação.

$\mathrm{Na}$ fase exploratória, se obteve informações relevantes a fim de subsidiar as fases seguintes, resultando no estudo da situação ou do problema em questão, na verificação das necessidades dos interessados no projeto, além da divulgação da proposta. Nesta primeira etapa do processo foi trabalhado o referencial teórico com a equipe de pesquisadores; definiu-se como recorte do diagnóstico quantitativo da situação o quadro total de alunos matriculados nos quatro cursos do Centro de Ciências e Tecnologia/CCT.

Foi elaborado um questionário com perguntas fechadas e aplicado pela equipe de iniciação científica, através de visitas a todas as turmas dos cursos de Ciência da Computação, Engenharia Ambiental e Sanitária, Engenharia de Produção e Matemática. O levantamento de informações dos discentes do CCT foi elaborado no período aproximado de dois meses. A devolução dos resultados desta etapa foi apresentada através de banner exposto no hall dos cursos e na fase principal, durante o primeiro seminário do projeto, assim como através da participação da equipe em eventos internos, que complementou o processo de divulgação do projeto junto à comunidade acadêmica do CCT.

$\mathrm{Na}$ fase principal, "com o diagnóstico claro sobre a realidade da organização e dos eventos ou pontos que se desejava pesquisar”, os pesquisadores iniciaram a prática, 
através de seminários para guiar a ação (Richardson, 1999). Esta etapa de qualificação de ideias empreendedoras e de análise interativa dos projetos discentes foi realizada durante o I Workshop de Empreendedorismo do CCT.

$\mathrm{Na}$ terceira etapa foram ampliadas as sinergias e experiências práticas de construção coletiva do conhecimento e de formação crítica de cada indivíduo envolvido no processo. Esta foi considerada a etapa mais prática de todo processo. Nesta fase de ação concreta da pesquisa foram elaboradas diversas ações, tais como o desenvolvimento dos projetos discentes ou o encaminhamento de uma organização coletiva, como a criação de uma empresa júnior, ou de uma incubadora de projetos.

A quarta etapa, fase de análise e avaliação, passo final do processo, culminou com o II Workshop de Empreendedorismo, que teve como objetivo analisar o andamento das propostas, verificando seus resultados e consequências a curto e médio prazo, onde se fez possível a verificação de novos ensinamentos capazes de permear estudos futuros.

Para ter-se a adesão dos discentes, o primeiro e o segundo Workshop de Empreendedorismo foram realizados aos sábados, nos turnos da manhã e da tarde.

\subsection{Estratégias de tratamento e análise de dados}

A sistematização dos dados quantitativos coletados na fase exploratória gerou planilhas e gráficos, viabilizando o cruzamento com dados de matrícula e indicadores de áreas de interesse dos discentes em relação a formas de atuação prática na instituição, as áreas de atuação de suas ideias empreendedoras, as formas de apoio demandadas e o interesse em participar de iniciativas empreendedoras.

Para a coleta de dados qualitativos e registros das reflexões conjuntas foi utilizada a técnica Metaplan, aplicada a processos participativos de aprendizagem, planejamento e avaliações. Esta técnica facilita a participação, estimula a capacidade de síntese e socializa as contribuições dos participantes, além de registrar e documentar a discussão grupal. Os discentes em iniciação científica complementaram a coleta destes dados fazendo o trabalho de relatoria e registrando momentos relevantes dos eventos, de forma a enriquecer a análise e a sistematização do processo pela equipe de pesquisa. Registros fotográficos também contribuíram para a sistematização dos resultados das atividades coletivas.

As análises das ideias empreendedoras dos estudantes, realizadas com base em Matriz de Análise da Sustentabilidade (ver figura 1), foram sistematizadas através de planilhas e gráficos propiciando um estudo da relação dos projetos idealizados com os indicadores formulados. Esta matriz foi desenhada pela equipe do projeto, aborda a sustentabilidade através de indicadores técnicos, sociais e econômicos. Constituindo-se em ferramenta para se visualizar os pontos fortes e fracos dos projetos discentes no momento de uma primeira análise e de possibilitar posterior revisão desta análise a partir dos avanços empreendidos pelos autores dos projetos. 
Empreendedorismo: Monitoria e PICPE - 01 / Setembro / 2012 Projeto "Pesquisa-Açilo: Inovaçaco e Sustentabilidade das Iniciativas Discente do CCT UNIFESO"

WORKSHOP de EMPREENDEDORISMO

Matriz de Análise da Sustentabilidade e Qualificaçāo de Ideias Empreendedoras

Tendo em vista os objetvos do Projeto, de promover uma reflexão entre seus parbicipantes sobre ideias empreendedoras e de contribuir para a qualificaçăo e implementaçăo destas ideias, bem como 0 entendimento da importảncia do Empreendedorismo como prática que deve integrar inovaçảo $\theta$ desenvolvimento sustentável, a presente Matriz foi elaborada de modo a promover a análise de ideias empreendedoras em relaçăo a três indicadores centrais de sustentabilidade: relevância do ideias, viabilidade e capacidade de integraçảo.

Relevância - analisa os impactos sociais, ambientais, económicos, técnicos e territoriais.

Viabilidade - verifica se há ambiência favorível ao desenvolvimento da ideia e facilidades para sua implementação.

Integraçăo - estuda a interdisciplinaridade das ideias e as possiveis interfaces dentre os cursos do CCT e demais cursos da instituiçăo.

É possivel atribuir até 25 pontos para cada um dos très fatores.

RELEVÃNCIA

Atribuir a cada um dos indicadores de relevância de um a cinco pontos. O resultado da soma dos pontos dos cinco indicadores corresponde à pontuaçáo geral do Fator Relevância da ideia.

Pontuaçäo: 1 -irrelevante; 2 - pouco relevante; 3 - relevante; 4 muito relevante; 5 totalmente relevante Inovaçăo

Abrangência locallregional

Perspectiva ambienta

Alcance social

Contribuiçäo econômica: (Gera trabaho e Renda?)

\section{VIABILIDADE}

Atribuir a cada um dos indicadores de viabiidade de um a cinco pontos. O resultado da soma dos pontos dos cinco indicadores corresponde à pontuaçáo geral do Fator Viabilidade da idéia.

Pontuaçâo: 1 - inviável ; 2 - pouco viävel; 3 - viävel; 4 - muito viável; 5 - extremamente viável

Técnica

Econômica (Investimento inicial)

Aspectos legais

Mercado favorível (existe mercado consumidor? 0 público alvo é acessivel?

Impacto acadêmico (contribuiçăo nos processos de fomaçâo, ensino e da pesquisa)

\section{INTEGRAÇAOO}

Atribuir pontuaç̧o correspondente ao tem assinalado.

Pontuaça: 5 pontos para um curso; 10 pontos - para dois cursos; 15 pontos para treses cursos; 20 pontos pare quatro cursos; 25 pontos para cinco ou mais cursos.

Envolve um curso

Envolve dois cursos

Envolve trés cursos

Envolve quatro cursos

Envolve cinco ou mais cursos

RESULTADOS DA ANÁLISE:

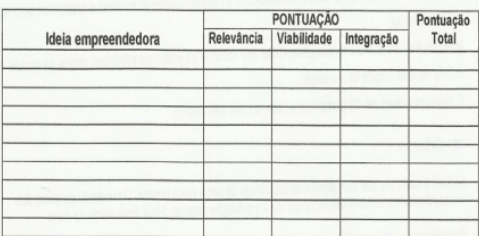

GRUPO:

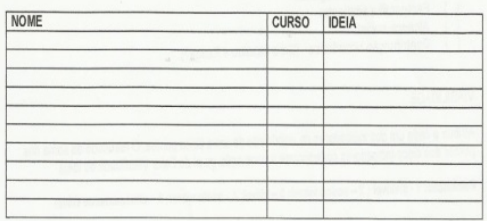

Figura 1 - Matriz de Análise da Sustentabilidade

O conjunto de dados coletados, além de subsidiar os projetos individuais na Fase de Ação, possibilitou vislumbrar ações coletivas em prol de novos cenários de aprendizagem empreendedora no âmbito da instituição.

Os dados obtidos neste estudo foram ordenados, qualificados e quantificados, com vistas a permitir a elaboração de um banco de dados de Empreendedorismo do CCT do UNIFESO. Todos os dados tratados foram disponibilizados ao corpo docente, de modo a contribuir para o aperfeiçoamento de atividades formativas, em termos teórico e prático. 


\section{Resultados e Discussão}

Através da aplicação de questionários junto aos alunos dos quatro cursos do CCT, na fase exploratória do projeto foram apurados dados sobre os seguintes aspectos: alunos respondentes por curso e período; gênero e faixa etária; atividades práticas desenvolvidas por estes ligadas à formação em curso; existência de ideias que gostariam de implementar e áreas a que estariam relacionadas; tipo de apoio que julgam necessário; e interesse em desenvolver alguma atividade empreendedora. Uma significativa mostra de $30 \%$ dos alunos dos 634 alunos matriculados no primeiro período de 2012 respondeu às questões formuladas.

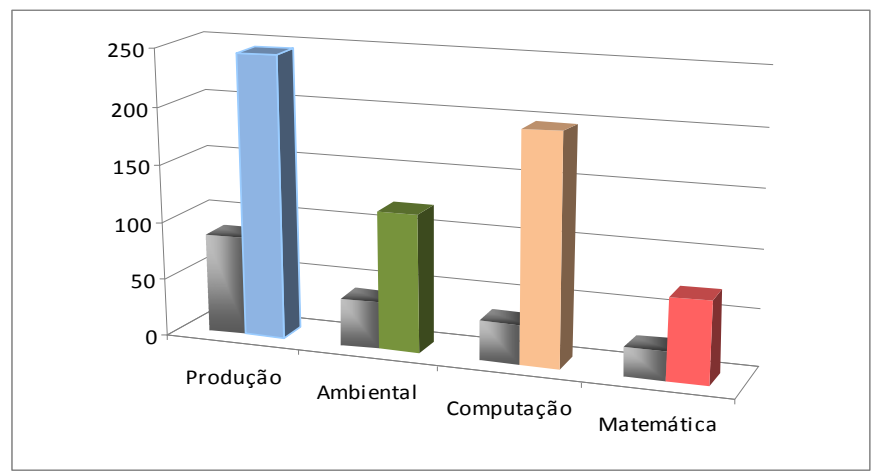

Figura 2 - Relação Numérica dentre alunos entrevistados e totais alunos matriculados por curso CCT

Comparando as respostas dos discentes por cursos (Figura 2), verificou-se que 18\% dos alunos de Ciência da Computação responderam ao questionário, ao passo que entorno de 35\% dos estudantes matriculados nos cursos de Engenharia Ambiental e Sanitária, Engenharia de Produção e Matemática participaram do diagnóstico. Analisando o perfil dos alunos do Curso de Ciência da Computação, tradicionalmente uma área de atuação muito empreendedora, ficou diferenciado dos demais cursos, em termos de receptividade e talvez tivéssemos que trabalhar estratégias diferenciadas de mobilização deste grupo.

Em relação ao desenvolvimento de atividades práticas ligadas à formação aproximadamente 55\% dos pesquisados responderam que não desenvolviam nenhum tipo de atividade, o que pode ser compreendido quando verificamos que a maior percentagem de participantes do diagnóstico cursava os primeiros períodos. Contudo, $52 \%$ do total de entrevistados afirmou ter uma ideia empreendedora a desenvolver.

Em relação ao apoio que julgam necessário para desenvolver seus projetos, as demandas por orientação técnica, 37,7\%, e por apoio em termos de infraestrutura, 31\%, são colocadas em primeiro plano, seguidas de subsídios teóricos, 18\%, interdisciplinaridade e pesquisa, $17,5 \%$. Respostas que sinalizaram a demanda por novos cenários de aprendizagem e interação dos diferentes atores do corpo 
institucional. Já a opção apoio motivacional foi colocada em último plano, sendo assinalada por $9,3 \%$ dos pesquisados.

Na fase principal o trabalho de divulgação do projeto foi intensificado, tendo em vista a realização do I Workshop de Empreendedorismo. Além de discentes do CCT, participaram deste evento cinco alunos do curso de Ciências Biológicas/ CBio. Participaram ainda dois docentes do CCT e um docente do CBio (Figura 2). Sobre o número total de participantes no Workshop, observou-se a grande representatividade dos discentes da Engenharia de Produção, 48\% (Figura 3), sendo que grande parte dos participantes estava cursando os primeiros períodos dos respectivos cursos.

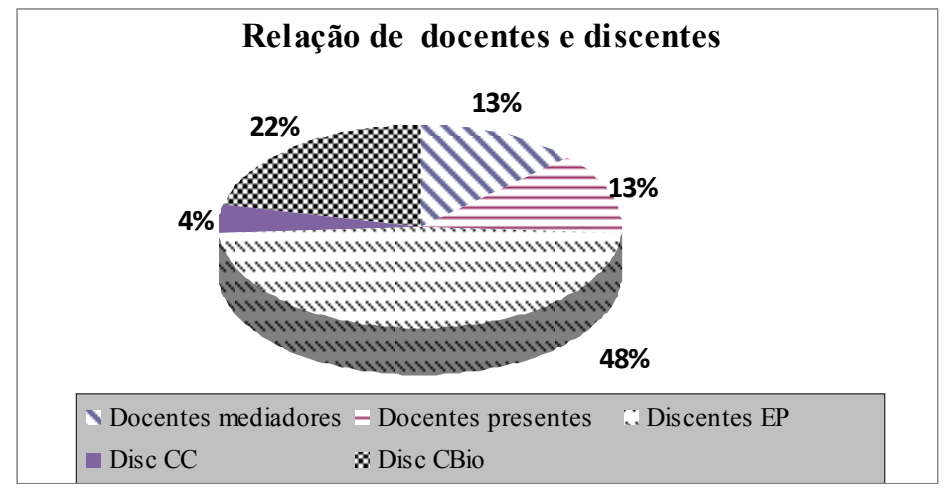

Figura 3 - Relação percentual de docentes e discentes Participantes do I Workshop

A participação dos discentes do CCT foi considerada significativa, mas, verificou-se uma baixa participação da Ciência da Computação, de um único aluno participante da equipe do Projeto. Nenhum aluno da Engenharia Ambiental e Sanitária participou do evento.

Dez ideias empreendedoras foram apresentadas pelos participantes e agrupadas por critérios de similaridade definidos coletivamente. Os participantes se reuniram por afinidade com os grupos de ideias formados. No total foram formados quatro grupos distintos de projetos, denominados: Fontes Alternativas de Energia; Processos Sustentáveis; Negócios Econômicos; e Negócios Acadêmicos. As ideias foram analisadas e pontuadas quanto à sua sustentabilidade considerando indicadores de relevância, viabilidade e integração.

Na Fase de Ação foram desenvolvidas diversas atividades lideradas pela equipe do projeto, dentre as quais a elaboração de documentos para apresentação e publicação dos resultados parciais do projeto; a participação em eventos como a Semana Nacional de Ciência e Tecnologia - SNCT e a II Jornada de Pesquisa e Iniciação Científica JOPIC; uma visita técnica Pontifícia Universidade Católica do Rio de Janeiro / PUCRio; e elaboração do I Seminário de Empreendedorismo do CCT / UNIFESO.

Entre 18 e 21 de outubro de 2012, foi realizada uma atividade dentro da Semana Nacional de Ciência e Tecnologia- SNCT, na Praça Olímpica de Teresópolis, RJ, com a participação do UNIFESO. A SNCT estava sobre a coordenação da Secretaria de Educação, Ciência e Tecnologia, Meio Ambiente, e da Casa da Ciência da Universidade 
Federal do Rio de Janeiro, UFRJ. Este trabalho apresentado na SNTC teve o objetivo de incentivar o empreendedorismo, como caminho para o desenvolvimento da cidade de Teresópolis, a fim de divulgar o PICPE e o potencial dos diversos Cursos de Graduação do UNIFESO. Na ocasião do evento, discentes e docentes do projeto apresentaram o estudo da pesquisa-ação ao público em geral, através de Banner com resultados da Fase Exploratória. Esta participação também possibilitou à equipe manter articulações com representantes dos demais projetos de pesquisa em desenvolvimento na instituição e contatos com representantes de outras instituições locais que visitaram o stand.

Nos dias 26 e 27 de outubro de 2012, foi realizada a II Jornada de Pesquisa e Iniciação Científica do UNIFESO - JOPIC 2012, no campus sede, com o objetivo de promover e incentivar a cultura de pesquisa, estimular a produção acadêmica e o aprimoramento da formação de profissionais e estudantes do Centro Universitário Serra dos Órgãos / UNIFESO. A apresentação de todos os projetos de pesquisa em andamento na instituição promoveu a troca de experiências, socialização de resultados, preparação e apresentação dos resultados como um exercício de comunicação para a iniciação científica dos discentes pesquisadores, além da avaliação dos projetos por especialistas externos.

A participação na II JOPIC mobilizou os integrantes da equipe, desde a preparação de relatório parcial dos resultados e resumo expandido para publicação, até a elaboração de um roteiro e a apresentação do projeto Pesquisa - Ação: Inovação e Sustentabilidade das Iniciativas Discentes. Ao término da apresentação houve um debate entre a banca avaliadora e os integrantes do grupo, demais discentes e docentes presentes, ficando evidenciada a grande importância para o desenvolvimento dos discentes do CCT e dos demais centros do UNIFESO.

No dia primeiro de novembro de 2012, o projeto promoveu uma visita técnica representada por docentes e discentes dos cursos de Ciência da Computação, Engenharia Ambiental e Sanitária e Engenharia de Produção. A visita fez parte dos preparativos do I Seminário de Empreendedorismo do CCT e, também, teve por objetivos estreitar contatos com seus líderes e conhecer preliminarmente o funcionamento de uma incubadora de empresas e de uma empresa júnior. Os representantes do nosso projeto puderam ter contato com algumas empresas em diferentes fases do processo de incubação e, ainda, visitaram o espaço de atuação dos discentes da Empresa Junior da PUC-Rio, acompanhados por seu presidente em 2012.

O I Seminário de Empreendedorismo do CCT / UNIFESO, realizado no dia 8 de novembro de 2012, no campus Pró-Arte, aberto a toda a comunidade acadêmica do UNIFESO, teve como objetivo principal mobilizar a comunidade acadêmica para a importância de novos cenários de aprendizagem com ênfase no envolvimento discente.

Além de motivar discentes e docentes presentes para a participação no evento final do projeto. O programa do I Seminário de Empreendedorismo do CCT teve as seguintes atividades: abertura pela direção do Centro de Ciências e Tecnologia / CCT; palestra "Práticas empreendedoras de sucesso: Instituto Gênesis PUC-Rio" e palestra sobre experiência da Empresa Junior na PUC-Rio. Em seguida, houve a apresentação de vídeo realizado por integrantes discentes do Projeto com seus objetivos, conceitos centrais e depoimentos da equipe; além de mostra "Prata da Casa" que apresentou 
empreendedores culturais da comunidade acadêmica do CCT; e, encerrando com um coquetel oferecido aos presentes.

A primeira palestra mostrou os ganhos possíveis para empresas geradas e fortalecidas no processo de incubação e, também, os ganhos crescentes para a instituição que abriga uma incubadora. Os participantes, em sua maioria os docentes do UNIFESO, buscaram aprofundar com o palestrante detalhes sobre resultados e processos necessários à criação e ao desenvolvimento da experiência. No caso da experiência da Empresa Junior, o palestrante versou sobre as linhas de ação da organização, estratégias desenvolvidas e principais projetos implementados, provocando os discentes presentes a discutirem e buscarem com os dois palestrantes convidados mais informações sobre o processo de criação e de manutenção de uma empresa júnior.

A partir deste seminário foram obtidos entre outros os seguintes resultados: (i) subsídios gerados para a conclusão do projeto; (ii) mobilização da comunidade acadêmica, em especial o corpo discente da instituição para reflexão sobre a importância da criação de uma empresa júnior; (iii) estreitamento de contato apontando para possíveis parcerias com as iniciativas da PUC-Rio; (iv) revelação de talentos musicais de discentes e docente do CCT, e motivação de outros, que apontaram para a organização de uma mostra cultural do UNIFESO em 2013; e (v) reação muito positiva de toda a comunidade acadêmica do Campus Pró-arte, incluindo funcionários e gestores, gerada pela mobilização alcançada pelo conjunto das atividades desenvolvidas durante todo o evento, e amplamente comentada durante o coquetel de encerramento.

O processo de avaliação aconteceu durante todas as etapas do projeto, culminando com o II Workshop de Empreendedorismo, realizado no dia 10 de novembro de 2012. Esta atividade consistiu na principal ação da Fase de Avaliação do projeto e ainda focalizou desdobramentos da Fase de Ação.

No II Workshop de Empreendedorismo do projeto (Figura 4) o processo de avaliação foi estruturado com base em dois focos principais: integração e iniciativas dos participantes e criação de uma empresa júnior/EJ. Tendo como metas: (I) ampliar a mobilização da comunidade acadêmica; (ii) acompanhar o andamento dos projetos empreendedores analisados no I Workshop de Empreendedorismo; e (iii) articular sinergias entre docentes e discentes do CCT e dos demais Centros do UNIFESO em direção à criação de uma Empresa Junior, aberta aos estudantes de todos os cursos da Instituição.

O evento contou com 21 participantes. Compareceram 16 estudantes do CCT, número muito abaixo do esperado em vista de chuva intensa e constante acometida da data. Contudo, o grupo discente presente representou de forma equilibrada os três cursos principais do CCT, Engenharia Ambiental de Sanitária; Engenharia de Produção; e Ciência da Computação, o que consistiu num importante avanço em relação ao I Workshop. Compareceram, ainda, 3 docentes do CCT, além dos 3 docentes da equipe do projeto. Neste II Workshop não se contou com a presença de estudantes do Curso de Ciências Biológicas, devido a evento deste curso na mesma data.

Os trabalhos do II Workshop foram iniciados com a apresentação dos resultados parciais do projeto pela equipe, seguida de dinâmica de integração entre os 
participantes, quando discentes e docentes presentes se apresentaram e expuseram suas expectativas.

Num segundo momento foram discutidos os avanços das ideias empreendedoras analisadas no primeiro workshop. Os participantes se dividiram em subgrupos a partir do agrupamento original das ideias empreendedoras apresentadas e discutidas no primeiro workshop, incluindo no trabalho dos subgrupos de apresentação e discussão de novas ideias trazidas pelos participantes. Os grupos apresentaram as ideias e suas análises em plenária de socialização, ainda na parte da manhã (Figura 4).

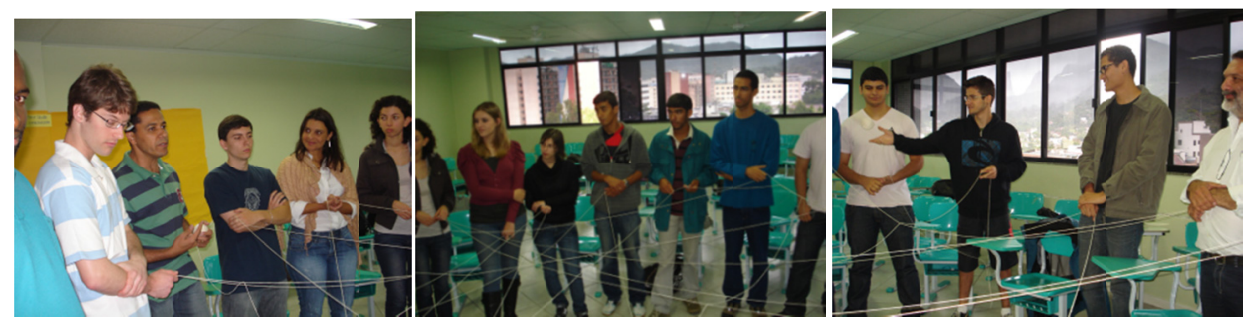

Figura 4 - Dinâmica da Rede, aplicada durante o II Workshop de Empreendedorismo

Na parte da tarde, a partir dos debates e das ideias surgidas no trabalho dos subgrupos, se encadeou a discussão para a criação de uma empresa júnior/ EJ. Vale registrar a importância do evento no que tange ao acompanhamento das iniciativas empreendedoras identificadas, o que possibilitou um avanço considerável das atividades seguintes, voltadas à criação da Empresa Junior UNIFESO.

Estudantes e professores discutiram serviços que poderão ser prestados pela empresa júnior, alguns relacionados às ideias discutidas e outros relacionados a demandas no campo de atuação de alguns dos estudantes presentes, como por exemplo: atividades de educação ambiental no SESC e assessoria à Prefeitura no campo da sistematização e do controle de informações (Figura 5).

Sobre a estruturação da empresa júnior, diversos aspectos puderam ser discutidos nesta fase, dentre os quais se destacaram: a introdução sobre o tema da empresa júnior, agora feita por representantes discentes; a formação de grupo de trabalho pró Empresa Junior do UNIFESO, incluindo discentes presentes e docentes apoiadores; e o delineamento dos próximos passos do Grupo de Trabalho da Empresa Junior, o GT-EJ / UNIFESO (Figura 5). Inicialmente o GT-EJ / UNIFESO foi composto por duas comissões:

- Uma destinada à estruturação da empresa, incluindo pesquisa sobre documentação e trâmites legais para criação da empresa júnior e sua estrutura organizacional;

- E outra destinada à da articulação do GT com o meio acadêmico do UNIFESO, incluindo a mobilização de discentes e docentes, e o contato com experiências afins, em busca de trocas e parcerias. 
Ficou evidenciada atenção especial do GT ao Curso de Ciências Biológicas, já representado no primeiro workshop, e ao diálogo com a Empresa Junior dos cursos de Administração e Contabilidade, já existentes no UNIFESO.

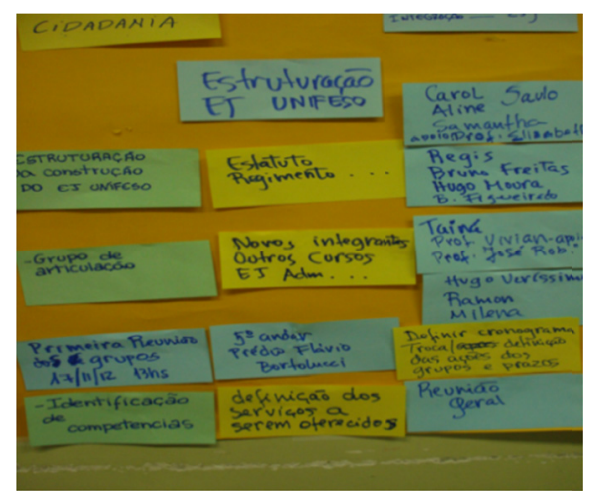

Figura 5 - Registro do Plano de Ação Pró- Empresa Junior do UNIFESO - Painel elaborado, através da técnica Metaplan, utilizada nos momentos coletivos do projeto

Concluiu-se da Fase de Avaliação que as perspectivas definidas pelos participantes, com o envolvimento e o comprometimento de todos com o processo futuro de criação de uma nova empresa júnior na instituição, foram indicadores positivos sobre o trabalho desenvolvido da pesquisa-ação, ao longo de 2012.

Os discentes que integraram a equipe do projeto em sua maioria mantiveram grande envolvimento, participando ativamente nas diversas atividades desta fase também, se engajando nas duas comissões do GT-EJ / UNIFESO e seguiram ativos e engajados nos trabalhos do grupo.

No segundo ano, com o acompanhamento participativo da criação da Enpresa Júnior, verificou-se uma contribuição significativa para a formação acadêmica e profissional dos estudantes envolvidos neste processo de atuação em uma empresa júnior. Inclusive houve contribuição relacionada às três dimensões do conhecimento elencadas por Paulo Freire: "a cognitiva, a das habilidades e a das atitudes" (Pereira, 2008).

Na dimensão cognitiva destacamos a busca por novos conhecimentos exigida pela própria atividade, tanto para a estruturação da empresa quanto para a realização de projetos de consultoria ou elaboração de palestras. Na dimensão das habilidades, podemos citar o exercício da profissão por meio da criação e gestão de um empreendimento e da efetiva atuação na elaboração de projetos de consultoria, de preparação de reuniões e negociação de trabalhos, entre outros. Na dimensão das atitudes, verificamos que, mesmo com todas as dificuldades enfrentadas pelo grupo, houve pró-atividade por parte dos estudantes envolvidos e vontade de tocar o empreendimento, além disso, os estudantes buscaram contatos externos com profissionais da área e empresas, negociaram parcerias e trabalhos. Enfim, a atividade com a empresa júnior possibilitou o exercício de habilidades que serão esperadas desses profissionais no mercado de trabalho. 
Uma das maiores dificuldades enfrentadas pelo grupo foi adaptar a atuação da EJ à realidade de estudantes de cursos noturnos, sendo que a maior parte dos discentes já desenvolve atividades durante o dia, estudando em terceiro turno, portanto, com pouco tempo livre. Esta condição de boa parte dos integrantes da EJ por si só já evidencia o perfil pró-ativo dos envolvidos nesse processo. Os discentes envolvidos são confrontados com seus limites, deparando-se com a necessidade de adequação de seu cotidiano e da administração do seu tempo, configurando um importante exercício da responsabilidade, que será demandada no mercado quando este concluir seu processo de formação.

Essas dificuldades provocaram a desistência de alguns membros pelo caminho. Mas, em geral, os participantes experimentaram a superação e tiveram a possibilidade de praticar conteúdos técnicos aprendidos em sala de aula, como gestão de pessoas, gerência de projetos, tecnologia da informação, entre outros, proporcionando a estes indivíduos uma elevação no padrão de conhecimentos específicos de sua área de atuação.

Numa proposta de avaliação participativa da experiência, o ponto de vista dos empresários juniores da Solução EJ expõe os benefícios da atuação em uma EJ para sua formação acadêmica. As respostas a um questionário aberto foram sistematizadas através da técnica de "análise do discurso do sujeito coletivo", que busca consolidar num só discurso-síntese homogêneo, redigido na primeira pessoa do singular (Lefèvre \& Lefèvre, 2003), a opinião da Empresa Junior Solução sobre a iniciativa, o processo de sua constituição e a participação dos discentes na empresa, conforme segue:

Sou estudante de graduação na área de ciências e tecnologia, atualmente atuo na Solução Empresa Junior de consultoria em uma função ligada à sua gestão. Adquiri conhecimentos o sobre o tema, através de eventos realizados na instituição de ensino onde estudo, tal como o workshop de empreendedorismo em que houve uma palestra ministrada por uma pessoa que já atuou em uma empresa júnior, por exemplo. Os professores que participaram do evento também ajudaram muito a agregar conhecimentos sobre o tema. Mas, também tenho contato com pessoas que fazem parte de empresas juniores de outras instituições.

O que me motivou a atuar na empresa foi a empatia pelo assunto $e$ a possibilidade de vivenciar a rotina de uma empresa, de forma a me preparar para minha atuação profissional futura. Além de sentir a necessidade de transformar os conhecimentos teóricos aprendidos na faculdade em aplicações reais, ainda na condição de discente, desenvolvendo habilidades empresariais, espirito de trabalho em grupo e espirito de liderança. A possibilidade de contribuir com mudanças na minha cidade também foi um fator de motivação.

Acredito que a atuação na empresa me possibilitará um diferencial no mercado de trabalho, pois as atividades que exerci na organização e estruturação da EJ Solução me proporcionaram um aprendizado que eu não teria somente assistindo aulas. Dentre as contribuições que recebi posso citar o desenvolvimento da minha capacidade criativa, da minha habilidade de 
comunicação e do meu empreendedorismo. Além de despertar-me uma curiosidade para áreas em que antes não pensava em atuar.

Ter a responsabilidade de um profissional na área me deixou mais próximo de empresas que futuramente pretendo trabalhar, possibilitou a ampliação da minha rede de contatos e permitiu o aperfeiçoamento de habilidades técnicas através de sua aplicação, seja na gestão de pessoas, na elaboração e aplicação de projetos de consultoria ou na manipulação de programas de computador como o Corel, por exemplo.

A atuação em uma empresa júnior contribui ricamente para a formação do Engenheiro, prepara-o para lidar com as situações do seu cotidiano, proporcionando um aprendizado constante, mostra na prática o que se aprende na teoria e, além dos benefícios já citados, ensina a solucionar problemas com autoridade e agrega uma bagagem de conhecimento no desenvolvimento de projetos.

\section{Considerações Finais}

Tendo em vista os resultados acima apresentados, consideramos que foram dados importantes passos para contribuir na formação de profissionais em C\&T, voltados ao desenvolvimento de ação, atitudes e competências empreendedoras sustentáveis.

A pesquisa-ação confirmou em sua fase exploratória a hipótese sobre a demanda dos discentes do CCT por apoio a suas ideias empreendedoras. Além disso, a pesquisa realizada gerou um banco de dados relevante sobre o perfil dos estudantes do Centro de Ciências. e Tecnologia - CCT / UNIFESO.

A partir do I Workshop, realizado na segunda etapa da pesquisa, o apoio e a participação de professores e estudantes do curso de Ciências Biológicas denotou que esta demanda também existia em relação àquele curso e que poderia ser válida dentre os demais cursos da instituição. Verificou-se que a disciplina Empreendedorismo oferecida pelo CCT como disciplina obrigatória das Engenharias e da Computação, e pelas Ciências Biológicas como eletiva, a partir de 2013, vem sendo ministrada nos cursos de Ciências Contábeis e Administração. Estas informações fizeram crer no ineditismo da experiência e, consequentemente, na necessidade de um trabalho mais ampliado de mobilização da comunidade acadêmica nesta direção.

Tal demanda ampliada, dos discentes do UNIFESO por apoio as suas ideias empreendedoras, poderão ser impulsionadas pelo próprio protagonismo estudantil, impulsionado por nosso projeto, e, com a criação de uma empresa júnior que envolva estudantes dos diversos cursos da instituição.

A formação de um grupo de trabalho para a criação de uma empresa júnior de amplo alcance na instituição, também poderá contribuir para minimizar o descompasso percebido entre a intenção de participação e a efetiva participação dos estudantes em atividades práticas. As lideranças estudantis que despontaram deste processo tornarse-ão exemplos a serem seguidos por outros estudantes, estimulando um maior empreendedorismo dentre o corpo discente, em especial do CCT. 
A parte o descompasso constatado do baixo número de discentes, a presença estudantil nos dois workshops realizados apresentou um alto padrão dos estudantes, com participação, opiniões e ideias empreendedoras de qualidade muito expressiva. $\mathrm{O}$ conjunto das ideias analisadas apresentou preocupações sociais e ambientais e com propostas que contemplaram a região serrana e em especial o município de Teresópolis, todas em sintonia com a necessidade de processos de desenvolvimento sustentável para a região serrana. Cabendo à Instituição o apoio efetivo a estas iniciativas discentes, como já refletiu também o próprio relatório do GT-EJ / UNIFESO.

A metodologia participativa e os instrumentos adotados na realização do projeto contribuíram para a validação das ideias apresentadas e para o empoderamento de seus autores, que a partir das discussões coletivas puderam perceber suas riquezas, bem como seus pontos fracos, e vislumbrar caminhos para a melhor qualificação e futura concretização das mesmas. Os instrumentos adotados e o método da PesquisaAção também contribuíram de forma efetiva para a iniciação científica da equipe discente, que apresentou depoimentos sobre ganhos pessoais e profissionais no processo desenvolvido, sob o enfoque interativo e da construção coletiva.

O intercâmbio possibilitado pela vivência dos workshops foi enfatizado pelos participantes docentes e discentes como necessário e pouco presente nos campus do UNIFESO. Ressaltaram a importância de intercâmbios entre discentes de diferentes centros e cursos, e de diferentes períodos da formação. Também foi destacada a necessidade de integração entre professores dos diversos Centros e a importância da interdisciplinaridade para a concretização de projetos sustentáveis.

Neste sentido, constituiu-se o grupo de trabalho para a criação de uma Empresa Junior na Instituição para dar suporte aos projetos discentes. Grupo este fortalecido por estudantes e professores dispostos, que já alavancaram esta ação e que, num segundo ano, lideraram o processo junto à comunidade acadêmica.

O acompanhamento participativo da criação da Empresa Júnior e as intervenções oferecidas constituíram-se em ferramentas de orientação e de direcionamento das atividades, colaborando para que a proposta não se perdesse no caminho. A metodologia de pesquisa-ação contribuiu na consolidação do objetivo proposto. As abordagens feitas desta perspectiva proporcionaram uma orientação das ações de acordo com informações adquiridas pelos próprios atores do processo, contribuindo com a motivação do grupo.

Verificamos a importância de seguir reforçando ações autogerenciadas para fortalecer o desenvolvimento da equipe e para favorecer uma dinâmica organizacional interativa, que favoreça abertura a novos participantes, necessários ao desenvolvimento de projetos e serviços aos futuros clientes da Solução EJ. O grupo já deu seus primeiros passos para articulação com o mercado.

\section{Agradecimentos}

Especiais agradecimentos aos demais integrantes da equipe do projeto: o professor Jussélio Rodrigues Ribeiro e os discentes Adriano Pinheiro de Souza Leal, Bruno Figueiredo Helum da Costa, Bruno Leonardo da Cruz Freitas, Saulo dos Santos Miller. 
Agradecemos, ainda, aos discentes e docentes participantes; aos coordenadores dos Cursos de Engenharia de Produção, Engenharia Ambiental e Sanitária, Ciência da Computação e Biologia; aos diretores dos Centros envolvidos no projeto; e à Diretoria de Pós Graduação, Pesquisa e Extensão do UNIFESO.

\section{Referências}

Freire, P. (1981). Educação e Mudança. Rio de Janeiro: Paz e Terra.

Lefèvre, F., \& Lefèvre, A. M. C. (2003). O discurso do sujeito coletivo: um novo enfoque em pesquisa qualitativa. Caxias do Sul: Editora EDUCS, 256p.

Miranda M. G., \& Resende, A. C. A. (2006). Sobre a Pesquisa-ação na Educação e as Armadilhas do Praticismo. Revista Brasileira de Educação, 1(33), Set./Dez.

Novaes, M. B. C., \& Gil, A. C. A. (2009). Pesquisa-Ação Participante Como Estratégia Metodológica para o Estudo do Empreendedorismo Social em Administração de Empresas. Revista de Administração Mackenzie Ram, 10(1), 134-160, Jan./Fev.

Pereira, C. M. (2008). Desenvolvimento em Equipe. Rio de Janeiro: Instituto SERE.

Richardson, R. J. (1999). Pesquisa Social - Métodos e Técnicas. 3.ed. São Paulo: Atlas.

Santos, B. de S. (2010). A Universidade do século XXI. para uma reforma democrática e emancipatória da Universidade. 3.ed. São Paulo: Cortez.

Thiolent, M. (1985). Metodologia da Pesquisa-Ação. São Paulo: Cortez. 